\title{
Increased Mortality in Patients Undergoing Inpatient Endoscopy During the Early COVID-19 Pandemic
}

\author{
Ysabel C. Ilagan-Ying ${ }^{1} \cdot$ Mariana N. Almeida $^{2} \cdot$ Arianna Kahler-Quesada $^{2} \cdot$ Lee Ying $^{3} \cdot$ Michelle L. Hughes $^{1,4}$. \\ Albert Do ${ }^{1,4} \cdot$ Kenneth W. Hung ${ }^{1,4}$ (1)
}

Received: 25 May 2021 / Accepted: 25 January 2022 / Published online: 19 February 2022

(c) The Author(s), under exclusive licence to Springer Science+Business Media, LLC, part of Springer Nature 2022

\begin{abstract}
Background and Aims The Coronavirus disease 2019 (COVID-19) pandemic led to the restructuring of most healthcare systems, but the impact on patients undergoing inpatient endoscopic procedures is unknown. We sought to identify factors associated with 30-day mortality among patients undergoing inpatient endoscopy before and during the first wave of the pandemic within an academic tertiary care center.

Methods We studied patients who underwent inpatient endoscopic procedures from March 1-May 31 in 2020 (COVID-19 era), the peak of the pandemic's first wave across the care center studied, and in March 1-May 31, 2018 and 2019 (control). Patient demographics and hospitalization/procedure data were compared between groups. Cox regression analyses were conducted to identify factors associated with 30-day mortality.

Results Inpatient endoscopy volume decreased in 2020 with a higher proportion of urgent procedures, increased proportion of patients receiving blood transfusions, and a $10.1 \%$ mortality rate. In 2020, male gender, further distance from hospital, need for intensive care unit (ICU) admission, and procedures conducted outside the endoscopy suite were associated with increased risk of 30-day mortality.

Conclusions Patients undergoing endoscopy during the pandemic had higher proportions of ICU admission, more urgent indications, and higher rates of 30-day mortality. Greater proportions of urgent endoscopy cases may be due to hospital restructuring or patient reluctance to seek hospital care during a pandemic. Demographic and procedural characteristics associated with higher mortality risk may be potential areas to improve outcomes during future pandemic hospital restructuring efforts.
\end{abstract}

Keywords Endoscopy $\cdot$ COVID-19 $\cdot$ Access to care $\cdot$ Gastrointestinal bleeding

\section{Introduction}

Ysabel C. Ilagan-Ying and Mariana N. Almeida contributed equally to this work.

Kenneth W. Hung

kenneth.hung@yale.edu

1 Section of Digestive Diseases, Department of Internal Medicine, Yale School of Medicine, 333 Cedar Street, New Haven, CT 06520, USA

2 Yale School of Medicine, New Haven, CT, USA

3 Department of Surgery, Yale School of Medicine, New Haven, CT, USA

4 Section of Digestive Diseases, Yale School of Medicine, New Haven, CT, USA
The Coronavirus disease 2019 (COVID-19) pandemic has drastically impacted the national healthcare system, including the restructuring of service lines and deferment of elective procedures to better triage inpatient care for patients with COVID-19. In response to the COVID-19 pandemic in the USA, national guidelines recommended postponement of elective and nonurgent endoscopic procedures. For example, risk stratification scores were used to prioritize hospital-based interventions for gastrointestinal (GI) bleeding compared to outpatient management until after the pandemic $[1,2]$. Recent studies across the globe have aimed to characterize the differences the COVID-19 pandemic may have caused for endoscopic procedures [3-6]. However, the impact of the pandemic on the provision of inpatient endoscopy is not yet fully elucidated, and studies have shown 
that patients and providers have anxiety about contracting COVID-19, which may alter patterns of seeking or providing care $[7,8]$. Though inpatient endoscopy risk is generally low [9], several studies have found differences in mortality rates and worse outcomes based on factors like weekend admissions, length of stay, distance to hospital traveled, and time to procedure [10-12]. In light of this uncertainty, we sought to characterize the effect of the COVID-19 pandemic on inpatient endoscopic procedures and assess risk factors for 30-day mortality in patients undergoing inpatient endoscopy before and during the initial pandemic wave at a critical period marked by lack of diagnostic testing, changing medical management policies, and early triaging mobilization efforts.

\section{Methods}

We constructed a retrospective cohort of patients $\geq 18$ years of age who underwent an inpatient endoscopic procedure at Yale New Haven Hospital, a 1,541 bed tertiary academic medical center, between March 1-May 31 in 2020 (COVID-19 era), defined as the first wave of the pandemic at the medical center, compared to the same time period from 2018 and 2019 (pre-COVID-19 era, combined after descriptive statistics confirmed no significant differences). Prior to August 2019, the GI consult service was staffed by gastroenterologists who rotated a week at a time, balancing their inpatient responsibilities with outpatient clinic demands. Starting in August 2019, the GI consult service was run by GI hospitalists, board-certified gastroenterologists dedicated to inpatient consultative gastroenterology without any outpatient responsibilities. Patient demographics included age, sex, race/ethnicity, body mass index (BMI), and residence zip codes. Median income and distance from the hospital were determined using patient and hospital zip codes and 2020 US Census data $[13,14]$. The average distance from the hospital was determined in the years 2018/2019 and 2020 and categorized as a dichotomous variable. Patients were categorized as "far" from the hospital if the distance between their residential and hospital zip codes was greater than the average distance in the year of the endoscopic procedure. BMI was used to categorize patients into the following categories: Underweight/Normal (BMI $<24.9 \mathrm{~kg} / \mathrm{m}^{2}$ ), Overweight (BMI $\left.25.0-29.9 \mathrm{~kg} / \mathrm{m}^{2}\right)$, and Obese (BMI $\left.\geq 30.0 \mathrm{~kg} / \mathrm{m}^{2}\right)$. Median income was categorized based on the 2020 US Census income quintiles, with the first two quintiles combined due to the small number of patients in the first quintile in our cohort [15]. Comorbid conditions were determined by using the Charlson comorbidity index and further stratified into mortality risk groups: no risk (score 0), mild (score
$1-2$ ), moderate (score 3-4), and severe (score $\geq 5$ ) [16]. Additional covariables included GI consult time and day and blood transfusion within $72 \mathrm{~h}$ of the procedure.

Procedure data including procedure type, indication, time, day, and location were extracted using Provation Endoscopy Software (Provation Medical, Minneapolis, $\mathrm{MN})$. Procedures were categorized as Upper procedures (esophagogastroduodenoscopy [EGD], small bowel enteroscopy), Lower procedures (colonoscopy and sigmoidoscopy), and Endoscopic Retrograde Cholangiopancreatography (ERCP). Indications were grouped and further categorized as urgent (obstruction/volvulus, foreign body/ food impaction, cholangitis/biliary obstruction, and GI bleed) or nonurgent (GI symptoms, iron deficiency anemia, dysphagia, screening, abnormal imaging, and other). The Glasgow-Blatchford Score was calculated for patients with upper GI bleeding and further categorized as lower risk $(<6)$ and higher risk of requiring intervention $(\geq 6)$ [17]. Time to procedure was calculated from the time of GI consult to procedure start time. The primary outcome was 30-day mortality after the endoscopic procedure. The primary cause of death was grouped into 1 of 6 categories: bleed, sepsis, malignancy, cardiac, COVID-19, and other. Patient demographic and hospitalization data were extracted from the electronic medical record.

We calculated descriptive statistics between March-May 2020 and March-May 2018/2019 and identified demographic and procedure risk factors associated with 30-day mortality using two Cox regression analyses: (1) unadjusted models; (2) models adjusted for demographics, procedure characteristics, and comorbid diseases. These regression models were performed on patient cohorts (entire cohort of patients, patients with procedures in 2018/2019 and patients with procedures in 2020) and procedure cohorts (upper endoscopic procedures, lower endoscopic procedures, and ERCP). For the patient cohorts, each patient was included only once, retaining the first procedure undergone by a patient and omitting duplicate or subsequent inpatient procedures performed for a single patient. For the unadjusted model, we first assessed for a relationship between 30-day mortality and patient, procedural, and hospitalization factors in each of the cohorts. Variables with evidence of an independent relationship with 30-day mortality $(p<0.05)$ were included in the adjusted model for all individual cohorts, retaining demographic variables and variables associated with 30-day mortality on multivariate analysis. To determine the effect of known COVID-19 illness, we also completed a sensitivity analysis excluding patients with a confirmed diagnosis of COVID-19. Analyses were performed using Statistical Analysis System (SAS) Software, version 9.4 (Cary, NC). A $p$ value of $<0.05$ was considered statistically significant. This study was approved by the Institutional Review Board at Yale New Haven Hospital (\#200028373). 


\section{Results}

There were 1,741 patients who underwent inpatient GI procedures between March 1-May 31 across all three years (Table 1). There were 453 patients in 2020 compared to 1,288 in $2018 / 2019$. There were significantly fewer Black patients in 2020 compared to $2018 / 2019$ (13.9\% vs. $18.6 \%, p=0.02$ ), but no difference in age, sex, ethnicity, median income, BMI, or average distance from hospital. There were 18 patients (4.0\%) with confirmed COVID-19 diagnosis by PCR testing in 2020 during their inpatient stay. There was no difference between the years 2018/2019 and 2020 in Charlson Comorbidity Index scores.

There were 2,313 total inpatient GI procedures studied. There was a decrease in the number of procedures from 1,700 procedures in 2018/2019 to 613 procedures in 2020. Most patients undergoing inpatient procedures were admitted through the emergency department in both 2020 and in 2018/2019 (73.6\% vs. $73.9 \%, p=0.85)$. Remaining patients were admitted directly from clinic or transferred from another hospital. There was an increased proportion of urgent procedures in 2020 compared to 2018/2019 $(66.5 \%$ vs. $60.4 \%$, respectively, $p=0.01)$. There was also a higher proportion of cases performed outside of the endoscopy suite (such as the ICU or operating room) (12.9\% vs. $9.7 \%, p=0.03)$, ICU admissions $(27.1 \%$ vs. $22.7 \%$, $p=0.04)$, and transfusion rates for GI bleeds $(65.4 \% \mathrm{vs}$. $51.3 \%, p<0.0001$ ) in 2020 compared to $2018 / 2019$. There was no difference in the proportion of low or high-risk GI bleeds classified by Glasgow-Blatchford Score between $2018 / 2019$ and 2020. Average time from GI consult to procedure was shorter in 2020 compared to 2018/2019 ( $22 \mathrm{~h}$ vs. $26 \mathrm{~h}, p<0.001$ ), and the average time to urgent procedures was even shorter (19 h vs. $22 \mathrm{~h}, p<0.001)$. There was no difference in procedure type or indication. There was no difference in the proportion of procedures or consults made on the weekend or after-hours (5PM8 AM the next day) between 2020 and 2018/2019. Additionally, there was no difference in the average length of stay between 2020 and 2018/2019 (14.4 days vs. 12.8 days, respectively, $p=0.12$ ).

Thirty-day mortality was significantly higher in 2020 compared to $2018 / 2019(10.1 \%$ vs. $5.5 \%, p<0.001)$. There was no difference in the cause of patient mortality in 2020 compared to 2018/2019 (Table 1). In 2020, 7 patients (15.2\%) died of complications associated with their COVID-19 diagnosis. Demographic and procedure risk factors associated with increased risk of 30-day mortality in the overall cohort included: age over 65 (HR $2.25,95 \%$ CI $1.48-3.40, p=0.0001$ ), male gender (HR $1.81,95 \%$ CI $1.19-2.74, p=0.01$ ), the year 2020 (HR $1.8695 \%$ CI $1.22-2.84, p=0.004)$, farther distance from hospital (HR 1.75, 95\%CI 1.17-2.60, $p=0.01$ ), procedures completed after-hours (5 PM-8AM the next day) (HR 2.06, $95 \%$ CI $1.23-3.46, p=0.01$ ), procedures performed outside the endoscopy suite (HR 5.27, 95\% CI 3.12-8.90, $p<0.0001$ ), ICU admissions (HR 2.88, 95\% CI 1.83-4.52, $p<0.0001$ ), and COVID-19 diagnosis (HR 3.06, 95\% CI $1.29-7.28, p=0.01$ ). However, weekend consults (HR $0.43,95 \%$ CI $0.26-0.71, p=0.001)$ were associated with decreased risk of 30-day mortality (Table 2).

When stratifying by year, in 2020 male gender (HR $2.30,95 \%$ CI $1.11-4.76, p=0.02)$, farther distance from hospital (HR 1.98, 95\% CI 1.11-4.76, $p=0.02$ ), procedures performed outside the endoscopy suite (HR $6.54,95 \% \mathrm{CI}$ 2.55-15.45, $p<0.0001$ ), and ICU admission (HR 2.54, $95 \%$ CI 1.24-5.20, $p=0.01$ ) were associated with 30-day mortality. In comparison, there was no association of increased risk of 30-day mortality in 2018/2019 for farther distance from hospital (HR 1.56, 95\% CI 0.93-2.61, $p=0.09$ ). (Table 3 ). When stratifying by procedure type, the year 2020 (HR 2.00, 95\%CI 1.34-3.01, $p=0.001$ ) was associated with increased mortality only for upper endoscopic procedures (Supplementary Table 1).

For only urgent procedures (obstruction/volvulus, foreign body/food impaction, cholangitis/biliary obstruction, and GI bleed) in 2020, increased risk of 30-day mortality was associated with farther distance from the hospital (HR 3.02, 95\%CI 1.49-6.16, $p=0.002$ ), procedures completed on the weekends (HR 9.45, 95\%CI 1.87-47.89, $p=0.01$ ), procedures completed off the endoscopy suite (HR 3.78,95\%CI 1.68-8.51, $p=0.001$ ), and ICU admission (HR 2.78, 95\% CI 1.30-5.94, $p=0.01$ ). Consults completed on the weekends (5PM-8AM the next day) (HR $0.20,95 \% \mathrm{CI} 0.07-0.54, p=0.002)$ and 30 -day readmission (HR $0.15,95 \%$ CI $0.03-0.67), p=0.01$ ) were associated with decreased risk of 30-day mortality for patients undergoing urgent procedures in 2020 . There was no association with risk of mortality in $2018 / 2019$ for ICU admission (HR 1.46, 95\%CI 0.80-2.67, $p=0.22$ ), consults completed on the weekend, procedures completed on the weekend and 30-day readmission (Supplementary Table 2).

After removing individuals with confirmed COVID19 diagnosis among all urgent procedures, the year 2020 (HR 2.17 95\%CI 1.47-3.21, $p=0.0001$ ) was associated with an increased risk of 30-day mortality. In an analysis of patients without COVID-19 undergoing urgent procedures in 2020, farther distance from the hospital (HR 2.57, 95\%CI 1.29-5.11, $p=0.01$ ), procedures completed off the endoscopy suite (HR 3.36 95\%CI 1.49-7.58, $p=0.003$ ), and ICU admissions (HR 3.79 95\% CI $1.69-8.52, p=0.001)$ were associated with an increased risk of 30-day mortality whereas weekend consults (HR $0.3195 \% \mathrm{CI} 0.13-0.74, p=0.01)$ and 30-day re-admission (HR 0.17 95\%CI $0.04-0.72, p=0.02$ ) were associated 
Table 1 Descriptive characteristics of patients undergoing inpatient endoscopic procedures during spring 2018-2020

\begin{tabular}{|c|c|c|c|c|}
\hline & & $\begin{array}{l}\text { March-May } \\
2018+\text { March-May } \\
2019\end{array}$ & March-May 2020 & $p$ value \\
\hline \multicolumn{5}{|l|}{ Patient characteristics } \\
\hline Number of patients & $n$ & 1288 & 453 & \\
\hline \multirow[t]{2}{*}{$\operatorname{Sex}(\%)$} & Male & $662(51.4)$ & $236(52.1)$ & 0.79 \\
\hline & Female & $626(48.6)$ & $217(47.9)$ & \\
\hline Average Age (SD) & & $63.4(16.8)$ & $62.3(17.2)$ & 0.23 \\
\hline \multirow[t]{3}{*}{ Race (\%) } & White & 924 (71.7) & $329(72.6)$ & 0.01 \\
\hline & Black & $240(18.6)$ & $63(13.9)$ & \\
\hline & Other/Declined & $124(9.6)$ & $61(13.5)$ & \\
\hline \multirow[t]{2}{*}{ Ethnicity (\%) } & Hispanic & $144(11.2)$ & $63(13.9)$ & 0.12 \\
\hline & Non-Hispanic & $1144(88.8)$ & $390(86.1)$ & \\
\hline \multirow[t]{4}{*}{ Median household income by zip code (\%) } & $<\$ 46,000$ & $212(16.5)$ & $74(16.4)$ & 0.92 \\
\hline & $\$ 46,000-\$ 75,000$ & $461(35.8)$ & $158(35.0)$ & \\
\hline & $\$ 75,000-\$ 113,000$ & $495(38.4)$ & $173(38.3)$ & \\
\hline & $>\$ 113,000$ & $120(9.3)$ & $47(10.5)$ & \\
\hline \multirow[t]{3}{*}{ Body Mass Index } & Underweight + Normal & $476(37.0)$ & $178(39.4)$ & 0.68 \\
\hline & Overweight & $380(29.5)$ & $130(28.8)$ & \\
\hline & Obese & $425(33.0)$ & $143(31.6)$ & \\
\hline \multirow[t]{4}{*}{ Charlson comorbidity index } & None (score 0) & $62(4.9)$ & $28(6.4)$ & 0.50 \\
\hline & Mild (score 1-2) & $154(12.1)$ & $61(13.7)$ & \\
\hline & Moderate (score 3-4) & $181(14.2)$ & $58(13.0)$ & \\
\hline & Severe (score $\geq 5$ ) & $874(68.8)$ & $300(67.1)$ & \\
\hline COVID-19 Diagnosis (\%) & N/A & $18(4.0)$ & N/A & \\
\hline Average distance from hospital in miles (SD) & $26.2(102.9)$ & $18.4(21.7)$ & 0.11 & \\
\hline Average length of stay in days (SD) & & $12.8(22.4)$ & $14.4(20.8)$ & 0.12 \\
\hline 30-day readmission (\%) & & $323(25.1)$ & $109(24.1)$ & 0.67 \\
\hline 30-day mortality (\%) & & $71(5.5)$ & $46(10.1)$ & 0.001 \\
\hline \multirow[t]{6}{*}{ Principal diagnosis for mortality (\%) } & Bleed & $17(23.9)$ & $17(37.0)$ & 0.13 \\
\hline & Sepsis & $15(21.1)$ & $7(15.2)$ & 0.42 \\
\hline & Malignancy & $14(19.7)$ & $4(8.7)$ & 0.11 \\
\hline & Cardiac & $8(11.3)$ & $3(6.5)$ & 0.39 \\
\hline & Other & $17(23.9)$ & $8(17.3)$ & 0.40 \\
\hline & COVID-19 & N/A & $7(15.2)$ & N/A \\
\hline \multicolumn{5}{|l|}{ Procedure characteristics } \\
\hline Number of procedures & $n$ & 1700 & 613 & \\
\hline \multirow[t]{3}{*}{ Procedures $(\%)$} & Upper endoscopic procedures & $1055(62.1)$ & $366(59.7)$ & 0.39 \\
\hline & Lower endoscopic procedures & $398(23.4)$ & $144(23.5)$ & \\
\hline & ERCP & $248(14.6)$ & $103(16.8)$ & \\
\hline Procedures performed outside endoscopy suite (\%) & $165(9.7)$ & $79(12.9)$ & $\mathbf{0 . 0 3}$ & \\
\hline Intensive Care Unit Admission (\%) & & $386(22.7)$ & $166(27.1)$ & 0.04 \\
\hline Transfusions (\%) & & $561(33.0)$ & $250(40.8)$ & 0.001 \\
\hline \multirow[t]{2}{*}{ Day of consult (\%) } & Weekday & $1325(77.9)$ & $491(80.1)$ & 0.27 \\
\hline & Weekend & $375(22.06)$ & $122(19.9)$ & \\
\hline Time of consult (\%) & After-hours (5PM to 8AM) & $194(11.4)$ & $80(13.1)$ & 0.28 \\
\hline \multirow[t]{2}{*}{ Day of procedure $(\%)$} & Weekday & $1639(96.4)$ & $596(97.2)$ & 0.34 \\
\hline & Weekend & $61(3.6)$ & $17(2.8)$ & \\
\hline Time of procedure $(\%)$ & After-hours (5PM to 8AM) & $101(5.9)$ & $34(5.5)$ & 0.72 \\
\hline
\end{tabular}


Table 1 (continued)

\begin{tabular}{|c|c|c|c|c|}
\hline & & $\begin{array}{l}\text { March-May } \\
\text { 2018 + March-May } \\
2019\end{array}$ & March-May 2020 & $p$ value \\
\hline \multirow[t]{3}{*}{ Average time to Procedure-hours (SD) } & All procedures & $26.2(22.7)$ & $21.9(18.4)$ & $<0.001$ \\
\hline & Urgent & $22.3(21.2)$ & $18.7(16.4)$ & $<0.001$ \\
\hline & Non-urgent & $32.3(23.6)$ & $28.5(10.4)$ & 0.02 \\
\hline \multirow[t]{2}{*}{ Procedure Urgency (\%) } & Urgent & $1028(60.4)$ & $407(66.4)$ & 0.01 \\
\hline & Non-urgent & $672(39.5)$ & $206(33.6)$ & \\
\hline \multirow[t]{4}{*}{ Urgent $(\%)$} & Obstruction/volvulus & $19(1.8)$ & $9(2.2)$ & 0.49 \\
\hline & Bleed & $725(70.5)$ & $286(70.3)$ & \\
\hline & Foreign body & $53(5.2)$ & $14(3.4)$ & \\
\hline & Biliary obstruction/cholangitis & $230(22.4)$ & $98(24.1)$ & \\
\hline \multirow[t]{6}{*}{ Non-Urgent (\%) } & GI symptoms & $227(33.8)$ & $65(31.5)$ & 0.52 \\
\hline & Iron deficiency anemia & $181(26.9)$ & $60(29.1)$ & \\
\hline & Screening & $74(11.0)$ & $23(11.1)$ & \\
\hline & Dysphagia & $69(10.3)$ & $29(14.1)$ & \\
\hline & Abnormal imaging & $56(8.3)$ & $15(7.3)$ & \\
\hline & Other & $65(9.7)$ & $14(6.8)$ & \\
\hline \multicolumn{5}{|l|}{ Procedures with GI bleed indications } \\
\hline Number of procedures & $n$ & 725 & 286 & \\
\hline \multirow[t]{2}{*}{ Glasgow-Blatchford score } & Low risk $($ score $<6)$ & $93(12.83)$ & $26(9.1)$ & 0.09 \\
\hline & High risk (score $\geq 6$ ) & $632(87.2)$ & $260(90.9)$ & \\
\hline
\end{tabular}

$\mathrm{N} / \mathrm{A}=$ Not applicable; $\mathrm{SD}=$ Standard deviation; $\mathrm{ERCP}=$ Endoscopic Retrograde Cholangiopancreatography; GI = Gastrointestinal

with decreased risk of 30-day mortality (Supplementary Table 3).

Furthermore, for procedures performed for GI bleeding in 2020, 30-day mortality was significantly associated with farther distance from the hospital (HR 3.44, 95\%CI 1.60-7.41, $p=0.001$ ), COVID-19 diagnosis (HR 2.99, 95\%CI 1.13-7.93, $p=0.03$ ), procedures completed on the weekend (HR 10.53, 95\% CI 1.86-59.50, $p=0.01$ ), procedures completed off the endoscopy suite (HR 3.31, 95\%CI 1.42-7.69, $p=0.01$ ), and ICU admission (HR 3.92, 95\% CI 0.50-4.36, $p=0.002$ ). Weekend consults (HR 0.21, 95\% CI 0.07-0.68, $p$-0.01) and 30 -day readmission (HR $0.10,95 \%$ CI $0.01-0.83, p=0.03$ ) were associated with decreased risk of 30-day mortality in patients with GI bleeding. Among patients undergoing procedures for GI bleeding in 2018/2019, there was no association with risk of 30-day mortality with ICU admission (HR 1.50, 95\% CI 0.74-3.03, $p=0.26$ ), weekend consults, procedures completed on the weekend, and 30-day readmission. There was no increased risk of mortality for procedures with higher risk GI bleeds based on the Glasgow-Blatchford Score (Supplementary Table 4).

\section{Discussion}

The COVID-19 pandemic has dramatically affected clinical practice and provision of care including endoscopy with variations in urgent procedural volume [18]. Our study highlights how the COVID-19 pandemic impacted inpatient GI endoscopic procedures at a large tertiary care center in the spring of 2020, which was the highest peak of COVID-related hospitalizations in the healthcare system studied. Inpatient endoscopy volume likely declined due to hospital restructuring in which procedures for nonurgent indications, such as dyspepsia or unexplained diarrhea, were deferred when possible and the use of telephone or video consults rather than in-person consults, which may have affected provider decision-making. Although endoscopies continued to be performed for nonurgent indications, postponement or cancellation of nonurgent procedures occurred at the discretion of the consulting gastroenterologist. We found increased rates of 30-day mortality during the height of the COVID-19 pandemic (2020) compared to previous years. Factors that were associated with increased mortality risk in 2020 included: older age, increased distance from hospital, need for ICU 
Table 2 Factors associated with 30-day mortality among patients undergoing inpatient endoscopic procedures

\begin{tabular}{|c|c|c|c|c|c|}
\hline \multirow[b]{2}{*}{ Patient characteristics } & & \multicolumn{4}{|l|}{ Entire cohort } \\
\hline & & HR unadjusted (95\% CI) & $p$ value & HR Adjusted (95\% CI) & $p$ value \\
\hline \multirow[t]{2}{*}{ Age } & $<65$ & 1.00 & & 1.00 & \\
\hline & $\geq 65$ & $1.66(1.12-2.45)$ & 0.01 & $2.25(1.48-3.40)$ & 0.0001 \\
\hline \multirow[t]{2}{*}{ Gender } & Female & 1.00 & & 1.00 & \\
\hline & Male & $2.03(1.37-3.02)$ & 0.0004 & $1.81(1.19-2.74)$ & 0.01 \\
\hline \multirow[t]{2}{*}{ Ethnicity } & Non-Hispanic & 1.00 & & Not included & - \\
\hline & Hispanic & $0.83(0.44-1.54)$ & 0.55 & & \\
\hline \multirow[t]{3}{*}{ Race } & White & 1.00 & & Not included & \\
\hline & Black & $0.95(0.58-1.58)$ & 0.86 & & - \\
\hline & Other & $1.25(0.70-2.21)$ & 0.45 & & \\
\hline \multirow[t]{2}{*}{ Year } & $2018+2019$ & 1.00 & & 1.00 & \\
\hline & 2020 & $2.13(1.45-3.13)$ & 0.0001 & $1.86(1.22-2.84)$ & 0.004 \\
\hline \multirow[t]{2}{*}{ Patient Distance from Hospital* } & $\begin{array}{l}\text { Closer than Average Cohort Dis- } \\
\text { tance }\end{array}$ & 1.00 & & 1.00 & \\
\hline & $\begin{array}{l}\text { Farther than Average Cohort } \\
\text { Distance }\end{array}$ & $2.05(1.39-3.00)$ & 0.0002 & $1.75(1.17-2.60)$ & 0.01 \\
\hline \multirow[t]{4}{*}{ Median Income } & $\geq \$ 113,001$ & 1.00 & & not included & - \\
\hline & $\$ 75,001-\$ 113,000$ & $1.35(0.69-2.60)$ & 0.38 & & \\
\hline & $\$ 46,001-\$ 75,000$ & $1.13(0.58-2.20)$ & 0.73 & & \\
\hline & $\leq \$ 46,000$ & $0.95(0.43-2.06)$ & 0.89 & & \\
\hline \multirow[t]{3}{*}{ Body Mass Index } & Underweight + Normal & 1.00 & & & \\
\hline & Overweight & $1.13(0.72-1.76)$ & 0.61 & Not included & - \\
\hline & Obesity & $0.77(0.48-1.23)$ & 0.27 & & \\
\hline \multirow[t]{2}{*}{ COVID-19 Diagnosis } & No & 1.00 & & 1.00 & \\
\hline & Yes & $8.71(4.04-18.79)$ & $<0.0001$ & $3.06(1.29-7.28)$ & 0.01 \\
\hline \multirow[t]{4}{*}{ Charlson Comorbidity Index } & None (score 0) & 1.00 & & Not included & - \\
\hline & Mild (score 1-2) & $0.75(0.14-4.09)$ & 0.75 & & \\
\hline & Moderate (score 3-4) & $0.60(0.11-3.28)$ & 0.55 & & \\
\hline & Severe (score $\geq 5$ ) & $2.94(0.73-11.94)$ & 0.13 & & \\
\hline \multicolumn{6}{|l|}{ Procedure Characteristics } \\
\hline \multirow[t]{2}{*}{ Day of Consult } & Weekday & 1.00 & & 1.00 & \\
\hline & Weekend & $0.54(0.34-0.87)$ & 0.02 & $0.43(0.26-0.71)$ & 0.001 \\
\hline \multirow[t]{2}{*}{ Time of Consult } & Work Hours (8AM-5PM) & 1.00 & & 1.00 & \\
\hline & After-hours (After 5PM-8AM) & $1.66(1.12-2.46)$ & 0.01 & $1.14(0.75-1.71)$ & 0.54 \\
\hline \multirow[t]{2}{*}{ Day of Procedure } & Weekday & 1.00 & & 1.00 & \\
\hline & Weekend & $3.41(1.01-11.48)$ & 0.05 & $0.52(0.13-2.04)$ & 0.35 \\
\hline \multirow[t]{2}{*}{ Time of Procedure } & Work Hours (8AM-5PM) & 1.00 & & 1.00 & \\
\hline & After-hours 5PM-8AM next day) & $3.19(1.99-5.09)$ & $<0.0001$ & $2.06(1.23-3.46)$ & 0.01 \\
\hline \multirow[t]{2}{*}{ Urgency Level of Procedure } & Non-urgent & 1.00 & & 1.00 & \\
\hline & Urgent & $2.51(1.62-3.89)$ & $<0.0001$ & $1.50(0.95-2.41)$ & 0.09 \\
\hline \multirow[t]{2}{*}{ Location of Procedure } & In Endoscopy Suite & 1.00 & & 1.00 & \\
\hline & Off Endoscopy Suite & $12.98(8.65-19.48)$ & $<0.0001$ & $5.27(3.12-8.90)$ & $<0.0001$ \\
\hline \multirow[t]{2}{*}{ ICU Admission } & None & 1.00 & & 1.00 & \\
\hline & ICU admission & $5.75(3.94-8.39)$ & $<0.0001$ & $2.88(1.83-4.52)$ & $<0.0001$ \\
\hline \multirow{2}{*}{$\begin{array}{l}\text { Transfusion within } 72 \text { Hours of } \\
\text { Procedure }\end{array}$} & None & 1.00 & & 1.00 & \\
\hline & Transfusion & $3.13(2.15-4.57)$ & $<0.0001$ & $1.31(0.83-2.07)$ & 0.24 \\
\hline \multirow[t]{2}{*}{ 30-Day Readmission } & None & 1.00 & & Not included & - \\
\hline & Readmission & $0.71(0.44-1.15)$ & 0.17 & & \\
\hline
\end{tabular}

Bolded text are to highlight "statistically significant" values with $p$ values $<0.05$, suggesting a likely independent relationship between the independent variable and outcome of interest

*Average Distance from Hospital Cut Off-2018/2019: 26.2 miles, 2020: 18.4 miles 
admission, and procedures conducted outside the endoscopy suite.

We observed increased transfusion rates for GI bleeds, urgent cases, and ICU admissions in 2020. The higher rates of urgent cases and increased mortality in 2020 may be due to patients presenting later in their disease course due to fears of COVID-19 exposure or decreased access to healthcare. Hence, the need for transfusions likely reflects this increased population of unstable patients. The proportion of patients with comorbid conditions was not different in 2020 compared to 2018/2019 and having more "severe" comorbidities based on the Charlson comorbidity index did not increase risk of mortality. We can hypothesize that patients in 2020 may have appeared more acutely ill rather than having more chronic comorbidities, given that the Charlson comorbidity index does not measure acuity. This supports the current literature evidence that patients in 2020 were more ill and had a greater likelihood of presenting to the inpatient setting in later stages of their disease course [19, 20].

While patients moved from GI consult to procedure more quickly in 2020 , there were still higher mortality rates during the first wave of the pandemic, which coincided with the peak of COVID-related hospitalizations within our care center. The faster time from consult to urgent procedures may have been a result of hospital systems restructuring and triaging care to focus on urgent procedures and postponement of elective procedures to prioritize the increasing number of patients with COVID-19 infection. The presence of a gastroenterologist hospitalist model during the COVID-19 era may have accounted for the shorter time from consult to procedure. For urgent procedures, after hour consults had a two times higher risk and weekend procedures had a nine times higher risk of 30-day mortality, which was not seen in 2018/2019. This points to the increased severity of illness in patients presenting for urgent procedures and how staffing and triaging after-hours may affect mortality. When removing confirmed COVID-19 diagnoses, procedures completed on the weekend lost its association with mortality, although after hour consults remained at two times increased risk of mortality. We hypothesize that this may be due to severity of illness of patients presenting later in their disease course or due to postponement of after-hours procedures if not truly emergent to conserve resources and limit unnecessary risk. Notably, for urgent procedures for GI bleeds, the higher risk cases based on the Glasgow-Blatchford Score were not associated with increased risk of mortality, possibly because of appropriately triaging care for this population. The hospital reached a peak of 790 patients with COVID-19 infection in April 2020. Many units were transitioned into COVID19 ICU floors (at the peak of the first wave, 16 of 27 units were dedicated as COVID-19 spaces) to accommodate the need for additional ICU beds and negative pressure rooms, and elective procedures were reduced starting the week of March 16, 2020, in order to conserve personal protective equipment (PPE). In addition, the hospital studied utilizes a dedicated team of inpatient GI hospitalist physicians, which has been demonstrated to improve safety, length of stay, and increase access for patients [21]. In addition, complications as a result of COVID-19 illness may have contributed to the increased mortality. The lower proportion of Black patients in our cohort who underwent inpatient procedures may reflect differences in patient access to care. Recent studies have demonstrated how socioeconomic factors have disproportionately affected the Black population due to increased loss of employment and healthcare access during the pandemic [22].

This study has some limitations. COVID-19 infection may have had an impact on the higher rates of mortality seen in 2020. Although the proportion of patients with COVID-19 infection is low in our cohort, this is likely an underestimation due to the limited access to diagnostic testing during the first wave of the pandemic. Therefore, all patients receiving endoscopies were treated as if they had COVID-19 during this era with endoscopists donning full PPE (respirator, eye protection, gloves, and gown) during procedures. Thus, we cannot determine whether the presence of COVID-19 diagnosis led to the increase in mortality, rather than the hospital system structural changes that occurred at the same time. All patients undergoing procedures in the endoscopy suite and most patients in the ICU received anesthesia, so the effect of sedation on mortality could not be assessed. Due to the retrospective nature of this study, there is also the potential for residual confounding from unmeasured variables, such as procedural difficulty. We also did not evaluate the number or reasons for canceled or postponed nonurgent procedures. Future studies should assess the impact of cancellation or deferral of nonurgent procedures on patient-important outcomes. Further directions include analyzing the effect of the COVID-19 era on length of stay and mortality risk base on a comorbidity index, though these studies will likely need more time given the notable risk in prolonged hospital courses for current patients with COVID-19 infection.

Despite the aforementioned limitations, this study does have considerable strengths. Our study represents a large cohort of patients at a busy tertiary care center that was affected by the initial wave of the COVID-19 pandemic. This study has a broad scope, focusing on different endoscopic procedures with varying indications and urgency. Additionally, although there are recent studies that have focused on characterizing endoscopic procedure differences between 2020 and previous years [6], we aimed to determine risk factors associated with increased mortality risk to assess patient populations warranting greater recognition. This 
Table 3 Factors associated with 30-day mortality among patients undergoing inpatient endoscopic procedures performed during spring 2020 (COVID-19 era) compared to spring 2018-2019 (non-COVID era)

\begin{tabular}{|c|c|c|c|c|c|c|c|c|c|}
\hline \multirow[b]{2}{*}{$\begin{array}{l}\text { Patient charac- } \\
\text { teristics }\end{array}$} & & \multicolumn{4}{|l|}{$2018+2019$} & \multicolumn{4}{|l|}{2020} \\
\hline & & $\begin{array}{l}\text { HR unadjusted } \\
(95 \% \mathrm{CI})\end{array}$ & $p$ value & $\begin{array}{l}\text { HR adjusted } \\
(95 \% \mathrm{CI})\end{array}$ & $p$ value & $\begin{array}{l}\text { HR unadjusted } \\
(95 \% \mathrm{CI})\end{array}$ & $p$ value & $\begin{array}{l}\text { HR adjusted } \\
(95 \% \mathrm{CI})\end{array}$ & $p$ value \\
\hline \multirow[t]{2}{*}{ Age } & $<65$ & 1.00 & & 1.00 & & 1.00 & & not included & - \\
\hline & $\geq 65$ & $\begin{array}{l}1.63(1.00- \\
2.69)\end{array}$ & 0.05 & $\begin{array}{l}2.01(1.20- \\
3.80)\end{array}$ & 0.01 & $\begin{array}{l}1.69(0.90- \\
3.17)\end{array}$ & 0.10 & & \\
\hline \multirow[t]{2}{*}{ Gender } & Female & 1.00 & & 1.00 & & 1.00 & & 1.00 & \\
\hline & Male & $\begin{array}{l}2.01(1.22- \\
3.33)\end{array}$ & 0.01 & $\begin{array}{l}1.69(0.99- \\
2.86)\end{array}$ & 0.05 & $\begin{array}{l}2.23(1.16- \\
4.30)\end{array}$ & 0.02 & $\begin{array}{l}2.30(1.11- \\
4.76)\end{array}$ & 0.02 \\
\hline \multirow[t]{2}{*}{ Ethnicity } & Non-Hispanic & 1.00 & & Not included & - & 1.00 & & Not included & - \\
\hline & Hispanic & $\begin{array}{l}0.78(0.34- \\
1.79)\end{array}$ & 0.55 & & & $\begin{array}{l}0.90(0.35- \\
2.29)\end{array}$ & 0.83 & & \\
\hline \multirow[t]{3}{*}{ Race } & White & 1.00 & & Not included & - & 1.00 & & Not included & - \\
\hline & Black & $\begin{array}{l}1.30(0.74- \\
2.30)\end{array}$ & 0.37 & & & $\begin{array}{l}0.42(0.13- \\
1.38)\end{array}$ & 0.15 & & \\
\hline & Other & $\begin{array}{l}1.07(0.45- \\
2.50)\end{array}$ & 0.88 & & & $\begin{array}{l}1.21(0.53- \\
2.75)\end{array}$ & 0.65 & & \\
\hline \multirow{2}{*}{$\begin{array}{l}\text { Patient dis- } \\
\text { tance from } \\
\text { hospital* }\end{array}$} & $\begin{array}{l}\text { Closer than } \\
\text { Average }\end{array}$ & 1.00 & & 1.00 & & 1.00 & & 1.00 & \\
\hline & $\begin{array}{l}\text { Farther than } \\
\text { Average }\end{array}$ & $\begin{array}{l}1.88(1.14- \\
3.11)\end{array}$ & 0.01 & $\begin{array}{l}1.56(0.93- \\
2.61)\end{array}$ & 0.09 & $\begin{array}{l}1.93(1.05- \\
3.56)\end{array}$ & 0.03 & $\begin{array}{l}1.98(1.03- \\
3.79)\end{array}$ & 0.04 \\
\hline \multirow{4}{*}{$\begin{array}{l}\text { Median } \\
\text { income }\end{array}$} & $\geq \$ 113,001$ & 1.00 & & Not included & - & 1.00 & & Not included & - \\
\hline & $\begin{array}{l}\$ 75,001- \\
\quad \$ 113,000\end{array}$ & $\begin{array}{l}1.45(0.60- \\
3.51)\end{array}$ & 0.41 & & & $\begin{array}{l}1.24(0.46- \\
3.35)\end{array}$ & 0.68 & & \\
\hline & $\begin{array}{r}\$ 46,001- \\
\$ 75,000\end{array}$ & $\begin{array}{l}1.22(0.49- \\
3.00)\end{array}$ & 0.66 & & & $\begin{array}{l}1.02(0.37- \\
2.79)\end{array}$ & 0.97 & & \\
\hline & $\leq \$ 46,000$ & $\begin{array}{l}1.21(0.45- \\
3.27)\end{array}$ & 0.71 & & & $\begin{array}{l}0.64(0.17- \\
2.39)\end{array}$ & 0.51 & & \\
\hline \multirow[t]{3}{*}{$\begin{array}{l}\text { Body mass } \\
\text { index }\end{array}$} & $\begin{array}{l}\text { Under- } \\
\text { weight + Nor- } \\
\text { mal }\end{array}$ & 1.00 & & Not included & - & 1.00 & & Not included & - \\
\hline & Overweight & $\begin{array}{l}1.47(0.83- \\
2.59)\end{array}$ & 0.18 & & & $\begin{array}{l}0.72(0.33- \\
1.54)\end{array}$ & 0.39 & & \\
\hline & Obesity & $\begin{array}{c}0.85(0.46- \\
1.56)\end{array}$ & 0.60 & & & $\begin{array}{l}0.68(0.33- \\
1.44)\end{array}$ & 0.31 & & \\
\hline \multirow{2}{*}{$\begin{array}{r}\text { COVID-19 } \\
\text { diagnosis }\end{array}$} & No & & & & & 1.00 & & 1.00 & \\
\hline & Yes & & & & & $\begin{array}{l}5.60(2.47- \\
12.67)\end{array}$ & $<0.0001$ & $\begin{array}{l}2.10(0.84- \\
5.22)\end{array}$ & 0.11 \\
\hline \multirow{4}{*}{$\begin{array}{l}\text { Charlson } \\
\text { comorbidity } \\
\text { index }\end{array}$} & None (score 0) & $\begin{array}{l}\text { HR cannot be } \\
\text { determined }\end{array}$ & & Not included & - & 1.00 & & Not included & - \\
\hline & $\begin{array}{l}\text { Mild (score } \\
1-2)\end{array}$ & & & & & $\begin{array}{l}0.17(0.02- \\
1.91)\end{array}$ & 0.15 & & \\
\hline & $\begin{array}{l}\text { Moderate (score } \\
3-4 \text { ) }\end{array}$ & & - & & & $\begin{array}{l}0.37(0.05- \\
2.66)\end{array}$ & 0.33 & & \\
\hline & $\begin{array}{l}\text { Severe } \\
\quad(\text { score } \geq 5)\end{array}$ & & & & & $\begin{array}{l}1.18(0.28- \\
4.91)\end{array}$ & 0.82 & & \\
\hline \multicolumn{10}{|l|}{$\begin{array}{l}\text { Procedure } \\
\text { character- } \\
\text { istics }\end{array}$} \\
\hline \multirow[t]{2}{*}{ Day of consult } & Weekday & 1.00 & & 1.00 & & 1.00 & & Not included & - \\
\hline & Weekend & $\begin{array}{l}0.55(0.30- \\
0.99)\end{array}$ & 0.05 & $\begin{array}{l}0.49(0.27- \\
0.90)\end{array}$ & 0.02 & $\begin{array}{l}0.56(0.25- \\
1.26)\end{array}$ & 0.16 & & \\
\hline
\end{tabular}


Table 3 (continued)

\begin{tabular}{|c|c|c|c|c|c|c|c|c|c|}
\hline \multirow[b]{2}{*}{$\begin{array}{l}\text { Patient charac- } \\
\text { teristics }\end{array}$} & & \multicolumn{4}{|l|}{$2018+2019$} & \multicolumn{4}{|l|}{2020} \\
\hline & & $\begin{array}{l}\text { HR unadjusted } \\
(95 \% \mathrm{CI})\end{array}$ & $p$ value & $\begin{array}{l}\text { HR adjusted } \\
(95 \% \mathrm{CI})\end{array}$ & $p$ value & $\begin{array}{l}\text { HR unadjusted } \\
(95 \% \mathrm{CI})\end{array}$ & $p$ value & $\begin{array}{l}\text { HR adjusted } \\
(95 \% \mathrm{CI})\end{array}$ & $p$ value \\
\hline \multirow[t]{2}{*}{$\begin{array}{l}\text { Time of } \\
\text { consult }\end{array}$} & $\begin{array}{l}\text { Work Hours } \\
\text { (8AM-5PM) }\end{array}$ & 1.00 & & 1.00 & & 1.00 & & 1.00 & \\
\hline & $\begin{array}{l}\text { After-hours } \\
\text { (5PM-8AM) }\end{array}$ & $\begin{array}{l}1.89(1.01- \\
3.55)\end{array}$ & 0.05 & $\begin{array}{l}0.92(0.52- \\
1.61)\end{array}$ & 0.76 & $\begin{array}{l}2.17(1.18- \\
3.99)\end{array}$ & 0.01 & $\begin{array}{l}1.45(0.74- \\
2.83)\end{array}$ & 0.28 \\
\hline \multirow{2}{*}{$\begin{array}{l}\text { Day of proce- } \\
\text { dure }\end{array}$} & Weekday & 1.00 & & Not included & - & 1.00 & & 1.00 & \\
\hline & Weekend & $\begin{array}{l}2.28(0.31- \\
16.99)\end{array}$ & 0.42 & & & $\begin{array}{l}5.32(1.27- \\
22.32)\end{array}$ & 0.020 & $\begin{array}{l}0.78(0.17- \\
3.58)\end{array}$ & 0.75 \\
\hline \multirow[t]{2}{*}{$\begin{array}{l}\text { Time of proce- } \\
\text { dure }\end{array}$} & $\begin{array}{l}\text { Work Hours } \\
\text { (8AM-5PM) }\end{array}$ & 1.00 & & 1.00 & & 1.00 & & 1.00 & \\
\hline & $\begin{array}{l}\text { After-hours } \\
\text { (5PM-8AM) }\end{array}$ & $\begin{array}{l}3.85(2.01- \\
7.37)\end{array}$ & $<0.0001$ & $\begin{array}{l}2.03(1.09- \\
3.81)\end{array}$ & 0.03 & $\begin{array}{l}3.31(1.46- \\
7.50)\end{array}$ & 0.004 & $\begin{array}{l}2.09(0.81- \\
5.39)\end{array}$ & 0.13 \\
\hline \multirow{2}{*}{$\begin{array}{l}\text { Urgency level } \\
\text { of procedure }\end{array}$} & Non-urgent & 1.00 & & 1.00 & & 1.00 & & 1.00 & \\
\hline & Urgent & $\begin{array}{l}2.57(1.48- \\
4.47)\end{array}$ & 0.001 & $\begin{array}{l}1.51(0.83- \\
2.73)\end{array}$ & 0.18 & $\begin{array}{l}2.26(1.08- \\
4.74)\end{array}$ & 0.03 & $\begin{array}{l}1.16(0.51- \\
2.65)\end{array}$ & 0.73 \\
\hline \multirow[t]{2}{*}{$\begin{array}{r}\text { Location of } \\
\text { procedure }\end{array}$} & $\begin{array}{l}\text { In Endoscopy } \\
\text { Suite }\end{array}$ & 1.00 & & 1.00 & & 1.00 & & 1.00 & \\
\hline & $\begin{array}{l}\text { Off Endoscopy } \\
\text { Suite }\end{array}$ & $\begin{array}{l}12.60(7.38- \\
21.51)\end{array}$ & $<0.0001$ & $\begin{array}{l}4.48(2.26- \\
8.86)\end{array}$ & $<0.0001$ & $\begin{array}{l}13.12(6.95- \\
24.77)\end{array}$ & $<0.0001$ & $\begin{array}{l}6.27(2.55- \\
15.45)\end{array}$ & $<0.0001$ \\
\hline \multirow{2}{*}{$\begin{array}{l}\text { ICU Admis- } \\
\text { sion }\end{array}$} & None & 1.00 & & 1.00 & & 1.00 & & 1.00 & \\
\hline & ICU admission & $\begin{array}{l}6.05(3.72- \\
9.83)\end{array}$ & $<0.0001$ & $\begin{array}{l}3.07(1.72- \\
5.48)\end{array}$ & 0.0002 & $\begin{array}{l}6.16(2.79- \\
9.53)\end{array}$ & $<0.0001$ & $\begin{array}{l}2.54(1.24- \\
5.20)\end{array}$ & 0.01 \\
\hline \multirow{2}{*}{$\begin{array}{c}\text { Transfusion } \\
\text { within } 72 \\
\text { hours of } \\
\text { procedure }\end{array}$} & None & 1.00 & & 1.00 & & 1.00 & & 1.00 & \\
\hline & Transfusion & $\begin{array}{l}3.39(2.09- \\
5.49)\end{array}$ & $<0.0001$ & $\begin{array}{l}1.57(0.89- \\
2.78)\end{array}$ & 0.12 & $\begin{array}{l}2.62(1.42- \\
4.85)\end{array}$ & 0.002 & $\begin{array}{l}1.09(0.51- \\
2.34)\end{array}$ & 0.82 \\
\hline \multirow{2}{*}{$\begin{array}{l}\text { 30-Day read- } \\
\text { mission }\end{array}$} & None & 1.00 & & Not included & - & 1.00 & & 1.00 & \\
\hline & Readmission & $\begin{array}{l}0.93(0.52- \\
1.65)\end{array}$ & 0.81 & & & $\begin{array}{l}0.35(0.13- \\
0.99)\end{array}$ & 0.05 & $\begin{array}{l}0.42(0.15- \\
1.23)\end{array}$ & 0.11 \\
\hline
\end{tabular}

Bolded text are to highlight "statistically significant" values with $p$ values $<0.05$, suggesting a likely independent relationship between the independent variable and outcome of interest

*Average Distance from Hospital Cut Off-2018/2019: 26.2 miles, 2020: 18.4 miles

study adds to the growing literature on the effects of the COVID-19 pandemic on endoscopic procedures. Rather than the focus on specifically diagnosed patients with COVID19 , our study highlights considerations that should be made in early pandemic phases when disease course is unknown, diagnostic testing is scarce, and hospitals are challenged to restructure in response to an influx of uniquely affected patients. Further research is needed to better understand the impact of the COVID-19 pandemic during later eras with emerging vaccines and treatments.

As hospital systems continue to contend with the challenges of operating during a pandemic, this study shows that certain patients should be triaged for GI procedures with special care. Although this study is specific to the first wave of the COVID-19 pandemic in the year 2020 before consistent rapid inpatient RNA testing and vaccine administration was available, it demonstrates the effects any early pandemic and clinical service restructuring can have on patients in modern medicine and can inform how hospital systems should proceed to triage care as pandemic conditions continue to evolve and the backlog of postponed cases is subsequently addressed. In light of other potential pandemics or medical emergencies where quick triaging is necessary, at-risk patients, who may be presenting with greater severity in their illness, may be identified based on procedural and patient characteristics to help reduce mortality. Patients over the age of 65, who live farther from the hospital, who receive consults after-hours, or who need upper endoscopy procedures should be recognized as high-risk patients. Further study is needed to understand the effects of this evolving era on patient care, access, and health services-related outcomes as we continue to shift practice patterns to address delayed elective procedures and advanced presentations of diseases, particularly in vulnerable patient populations disproportionately affected by the COVID-19 pandemic. 
Supplementary Information The online version contains supplementary material available at https://doi.org/10.1007/s10620-022-07414-x.

\section{Declarations}

Conflict of interest The authors have no conflicts of interest to disclose.

\section{References}

1. Castro Filho EC, Castro R, Fernandes FF, Pereira G, Perazzo H. Gastrointestinal endoscopy during the COVID-19 pandemic: an updated review of guidelines and statements from international and national societies. Gastrointest Endosc. 08 2020;92:440-445. e6.

2. Laursen SB, Gralnek IM, Stanley AJ. Raising the threshold for hospital admission and endoscopy in upper gastrointestinal bleeding during the COVID-19 pandemic. Endoscopy. Oct 2020;52:930-931. doi:https://doi.org/10.1055/a-1202-1374.

3. Chiriac S, Stanciu C, Cojocariu C, et al. The impact of the COVID-19 pandemic on gastrointestinal endoscopy activity in a tertiary care center from Northeastern Romania. Healthcare (Basel). 2021;9:100.

4. Lauro A, Pagano N, Impellizzeri G, Cervellera M, Tonini V. Emergency endoscopy during the SARS-CoV-2 pandemic in the North of Italy: Experience from St. Orsola University HospitalBologna. Dig Dis Sci. 2020;65:1559-1561.

5. Becq A, Jais B, Fron C, et al. Drastic decrease of urgent endoscopies outside regular working hours during the Covid-19 pandemic in the Paris area. Clin Res Hepatol Gastroenterol. 2020;44:579-585.

6. Annadurai V, Blackett J, Freedberg D, Hur C, Green P, Lebwohl B. Characteristics and outcomes of endoscopies before and during the COVID-19 pandemic in New York. Dig Dis. 2021;Epub ahead of print.

7. Armellini E, Repici A, Alvisi C, et al. Analysis of patients attitude to undergo urgent endoscopic procedures during COVID-19 outbreak in Italy. Dig Liver Dis. 2020;52:695-699.

8. Moraveji S, Thaker A, Muthusamy V, Banerjee S. Protocols, personal protective equipment use, and psychological/financial stressors in endoscopy units during the COVID-19 pandemic: a large survey of hospital-based and ambulatory endoscopy centers in the United States. Gastroenterology. 2020;159:1568-1570.

9. Kim SY, Kim HS, Park HJ. Adverse events related to colonoscopy: Global trends and future challenges. World J Gastroenterol. Jan 2019;25:190-204.
10. Gupta A, Agarwal R, Ananthakrishnan AN. "Weekend effect" in patients with upper gastrointestinal hemorrhage: a systematic review and meta-analysis. Am J Gastroenterol. 01 2018:113:13-21.

11. Kelly C, Hulme C, Farragher T, Clarke G. Are differences in travel time or distance to healthcare for adults in global north countries associated with an impact on health outcomes? A systematic review. BMJ Open. 11 2016;6:e 013059.

12. Kim J, Doyle JB, Blackett JW, et al. Effect of the Coronavirus 2019 pandemic on outcomes for patients admitted with gastrointestinal bleeding in New York City. Gastroenterology. Sep 2020;159:1155-1157.e1.

13. US Census Bureau. 2020 Demographic Analysis. Available at: https://www.census.gov/programs-surveys/decennial-census/ about/coverage-measurement/da.html.

14. Njei B, Esserman D, Krishnan S, et al. Regional and rural-urban differences in the use of direct-acting antiviral agents for hepatitis c virus: the veteran birth cohort. Med Care. 04 2019;57:279-285.

15. Congressional Budget Office. The Distribution of Household Income, 2017. 2021. Available at: https://www.cbo.gov/publi cation $/ 56575$.

16. Huang Y-Q, Gou R, Diao T-S, et al. Charlson comorbidity index helps predict the risk of mortality for patients with type 2 diabetic nephropathy. J Zhejang Univ Sci B. 2014;15:58-66.

17. Blatchford O, Murray WR, Blatchford M. A risk score to predict need for treatment for upper-gastrointestinal haemorrhage. Lancet. Oct 14 2000;356:1318-21.

18. Otani K, Watanabe T, Higashimori A, et al. A questionnaire-based survey on the impact of the COVID-19 pandemic on gastrointestinal endoscopy in Asia. Digestion. Nov 10 2021:1-15.

19. Rosenbaum L. The untold toll - the pandemic's effects on patients without Covid-19. New England Journal of Medicine. Jun 11 2020;382:2368-2371.

20. Czeisler ME, Marynak K, Clarke KEN, et al. Delay or avoidance of medical care because of COVID-19-related concerns - United States, June 2020. MMWR Morb Mortal Wkly Rep. 2020;69:1250-1257

21. Hughes M, Sun E, Enslin S, Kaul V. The role of the gastroenterology hospitalist in modern practice. Gastroenterol Hepatol (N Y). 2020;16:571-576.

22. Lopez L, Hart L, Katz M. Racial and ethnic health disparities related to COVID-19. JAMA. 2021;325:719-720.

Publisher's Note Springer Nature remains neutral with regard to jurisdictional claims in published maps and institutional affiliations. 